\title{
La diversidad cultural en sociedades desiguales: un desafío contemporáneo
}

\author{
Hernán Salas Quintanal
}

Amaranta Arcadia Castillo Gómez, 2010

¿Acaso son humanos? Procesos identitarios en el capitalismo tardío. Coreanos y mexicanos en la Huasteca tamaulipeca

Universidad Autónoma de Tamaulipas, Instituto de Investigaciones Antropológicas-Universidad Nacional Autónoma de México, 392 pp.
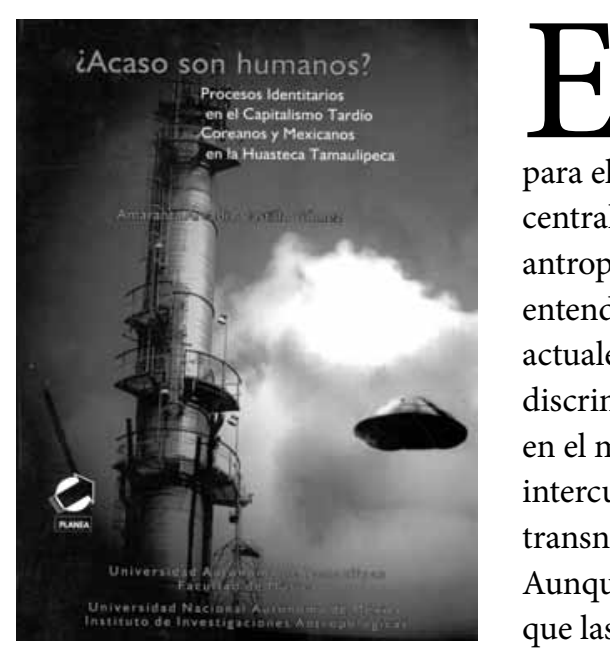
ste libro trata un problema de investigación verdaderamente atractivo para el público en general y central para las ciencias antropológicas interesadas en entender a las sociedades actuales: los procesos de discriminación y estigmatización en el marco de una interculturalidad y una transnacionalidad conflictivas. Aunque cada vez es más común que las sociedades estén

\footnotetext{
Cultural Diversity in Unequal Societies: A Contemporary Challenge

HeRnán Salas Quintanal: Instituto de Investigaciones Antropológicas, Universidad Nacional Autónoma de México, Distrito Federal, México hsalas@unam.mx
}

Desacatos, núm. 45, mayo-agosto 2014, pp. 154-157 interconectadas y por tanto conformadas por un proceso creciente de multiculturalidad, las relaciones que se establecen han agregado a los ya "tradicionales" conflictos de clase, de etnia, de género y de generación, los interculturales. El análisis de este tema, que parece persistente en la disciplina, rebasa el tratamiento exclusivamente teórico para indagar en los avatares de la vida social contemporánea, se inserta en el contexto problemático mundial caracterizado por la diferenciación social, la movilidad de los mercados laborales, los conflictos socioambientales, las migraciones, el llamado “adelgazamiento del Estado" y las transformaciones del nacionalismo, 
que unas veces debilita las soberanías nacionales y otras fortalece peligrosamente las identidades.

La interculturalidad mundial define un marco de convivencia entre las naciones que las jerarquiza, al mismo tiempo que amenaza las soberanías, debilita las identidades históricas y menoscaba una concertación global necesaria para promover la paz mundial. Estas circunstancias le permiten a la autora colocar los problemas culturales y otros de la sociedad tampiqueña y tamaulipeca - y huasteca- en el centro de un internacionalismo que supera la mera expansión de los mercados, como fue interpretado en décadas pasadas, para localizar el problema en la globalización de las prácticas culturales y políticas. Esto tiene su origen en la etapa del capitalismo tardío, que en nuestras sociedades ha sido bastante improvisado y ha dejado secuelas que vulneran a las poblaciones y debilitan los sistemas e instituciones. Sobran como muestra las oleadas de violencia y el deterioro del tejido social en la región.

Los procesos de petrolización, multiculturización y transnacionalismo corrieron paralelos al desarrollo capitalista en Tampico. El libro nos cuenta la historia local del petróleo, que - como el estaño en Bolivia, el caucho en el Amazonas, la ganadería en la Patagonia y el cobre en Chile - marcó la implantación de los espacios nacionales del capitalismo, como la industria azucarera, la del café, la del tabaco, la del algodón o la de las bananas a nivel regional, que al igual que el petróleo despertaron el interés de los países centrales durante las primeras décadas del siglo $\mathrm{xx}$ y tuvieron su representación local, de manera que la ciudad de Tampico tempranamente se ubica más en la lógica de las empresas extranjeras - holandesas, inglesas, estadounidenses- que en los vaivenes de la política nacional. La internacionalización del capital y de las relaciones comerciales generada por el establecimiento de los mercados globales agudiza la situación y las riquezas de Tampico son apetecidas por intereses que proceden de oriente, mediante una transnacionalización que cobra su lugar en todo el territorio nacional a través de diversas mercancías, incluyendo la mano de obra mexicana. Como un eufemismo, el cosmopolitanismo de Tampico - lo mismo que las ciudadescampamento que estudiaba Lins Ribeiro, encargadas de la construcción de grandes presas hidroeléctricas sobre el Paraná en la triple frontera de Brasil, Paraguay y Argentina, a la que se sumaron israelitas, italianos, estadounidenses, alemanes, y que desde un inicio hicieron acopio de símbolos transnacionales- incorporaba los símbolos nacionalistas de la Revolución Mexicana, los cuales ampliaban la base social y forjaban un tipo de sindicalismo más ligado a una ideología paternalista y corporativa, con privilegios y derechos laborales sobresalientes. Es interesante conocer de cerca los artificios, los recodos por donde transita y se instala el capitalismo. Esto conformó tanto a la clase trabajadora de los petroleros en todo el país como a la clase obrera mexicana, cuyas formas de explotación laboral no tenían ni remotamente las retribuciones de éstos.

Estas relaciones fueron fundamentales para comprender el desplazamiento estratégico de la mano de obra local, nacional e internacional que deviene de la reconfiguración de la Refinería Madero, donde puede observarse no sólo la flexibilidad de los procesos laborales sino cómo el capitalismo se rearticula y refuncionaliza las regiones $y$ localidades según intereses que no corresponden a las necesidades locales. En este sentido, la autora contribuye a entender la historia reciente del capitalismo con este caso que encuentra disponibilidad de población —ahí está la huasteca-, mano de obra campesina producto de la crisis de la agricultura, del campo y de la marginación rural y que padece condiciones de mayor debilidad, docilidad y 
abaratamiento. Las empresas multinacionales desarrollan estrategias innovadoras, lo que trae consigo cambios culturales locales, alteración en los productos y en las pautas de consumo. Esto, hay que apuntar, sólo es posible en regiones pauperizadas, aciaga fusión de crisis agrícola, deterioro ambiental, intensificación de las migraciones, abandono del Estado, circunstancias en las que la población sólo busca la subsistencia y en las que se registran amplios contingentes dispuestos a emplearse independientemente de condiciones, faenas y lugares. Como señalaba David Harvey más de 20 años atrás:

En forma paralela a la transformación de la estructura del mercado laboral, se han producido importantes cambios en la organización industrial. Por ejemplo, la subcontratación organizada ofrece oportunidades para la formación de pequeñas empresas y, en algunos casos, permite que los viejos sistemas de trabajo doméstico, artesanal, familiar (patriarcal) y paternalista (del tipo "padrino", del "gobernador" o de la mafia) revivan y florezcan como piezas centrales, y no ya como apéndices del sistema de producción (Harvey, 1998: 175-176).

El efecto de la extensión de la producción "a destajo", de economías "negras", "informales", clandestinas, subterráneas o ilícitas es transformar la modalidad del control sobre la mano de obra y el empleo, socavar la organización de la clase obrera y modificar la base para la lucha de clases. En otro orden de cosas, esta propuesta editorial estudia un caso aislado en apariencia - dicho sea de paso, abandonado por las investigaciones antropológicas en el país, como en Tampico y Tamaulipas- en su inserción internacional, hace una contribución significativa al estudio de las relaciones localesglobales en las cuales la articulación, casi siempre, ha sido definida por los mercados, pero que asume otro cariz en la medida en que este abatimiento de barreras comerciales ocurre paralelamente a un acercamiento de mundos diversos.

A partir del recorrido de la historia reciente de Tampico, Castillo Gómez va destacando aquellos elementos que explican su situación actual: el poblamiento, la composición étnica de la población, el origen de los inmigrantes, el establecimiento y desarrollo del comercio y de la vida industrial, la urbanización y las repercusiones de estos procesos en la vida social, hasta la modernización de las actividades económicas, de la vida urbana y de las identidades, para llegar a lo que llama y califica como "metrópoli del futuro" - al estilo de Lins Ribeiro-. Al mismo tiempo se hace una revisión de la historia de la actividad petrolera y de Petróleos Mexicanos en la región. En este marco actual de modernización tampiqueña se estudia y se comprende la “inserción" de la población coreana en el entorno ya multiculturalizado desde inicios del siglo pasado.

Después de describir este proceso desde lo macrosocial y la operación de los mercados laborales y financieros para instalar un proyecto transnacional de gran envergadura hasta el ámbito microsocial y las transformaciones de la sociabilidad tampiqueña desde la llegada de los coreanos en observables tan cotidianos como las formas culturales de la alimentación, la sexualidad, la vestimenta, la higiene, las creencias y demás hábitos, se incursiona en la discusión más significativa del estudio y que, en mi opinión, representa la contribución fundamental del libro: la conflictiva convivencia entre nativos y fuereños, es decir entre tampiqueños y coreanos. Con este análisis se recupera aquella vocación histórica de la antropología, tan necesaria en los tiempos que corren: entender la relación entre las diferencias culturales y establecer escenarios en los que convivan, sin destruirse las culturas involucradas las unas a las otras y sin debilitar las identidades de sus miembros. Con este trabajo se propone una etnografía innovadora, sin perder el encanto de la etnografía clásica. 


\section{Con base en estos procesos} puede establecerse hacia el final de la investigación la manera en que un grupo de mexicanos enfrenta la "amenaza" de otro diverso y se compacta bajo una misma estrategia, "como si" las diferencias se diluyeran ante un "enemigo" mayor y más poderoso. Se observa el encuentro entre identidades diversas, lo que permite examinar los factores externos que pueden definir la identidad, así como los internos que se ponen en juego y se actualizan cuando ésta se ve amenazada. Se aprecia la generación de un cúmulo importante de información y descripción acerca de los coreanos en el país. La exposición detallada ofrece la posibilidad de comprender a un grupo cada vez más presente en la sociedad mexicana y sobre el cual se producen prejuicios de manera permanente en la vida cotidiana, en las escuelas, en los medios de comunicación, en la vida política.
La reflexión contenida en este libro abre la oportunidad de crear un espejo en el cual ver reflejada la propia identidad nacional o, al menos, regional. A través de este contraste puede volverse la mirada hacia un cuestionamiento permanente sobre la mexicanidad, hacia el proyecto global de país y hacia la convivencia con otras naciones, culturas, sociedades. Esto hace inevitable reflexionar sobre la necesidad de observar de nuevo las etnias que habitan el país, a la luz de una multiculturalidad contemporánea que tiene su origen en la diversidad indígena, a la cual se suman los grupos de extranjeros y migrantes, cada vez más frecuentes.

En este sentido es sugerente leer cómo se ve el futuro de Tampico, la idea de una "metrópoli del futuro" - junto a Ciudad Madero y Altamira-, las inquietudes sobre la pervivencia de las actividades económicas y el desarrollo de las "habilidades" cosmopolitas de la población, y de qué manera éstas se ponen en ejercicio para enfrentar los retos que representa la llegada de otras poblaciones en el futuro, tanto o más diversas que la coreana, como el transcurso del mundo permite prever. La reflexión haría posible trasladar estas preocupaciones a otras regiones del país que experimentan transformaciones similares. Este libro es una historia reciente de las muchas que pueden escribirse del capitalismo en el ocaso del mismo o en el principio de nuevas formas de acomodar las relaciones laborales, productivas, interculturales y transnacionales.

\section{BIBLIOGRAFÍA}

Harvey, David, 1998, La condición de la posmodernidad. Investigación sobre los orígenes del cambio cultural, Amorrortu, Buenos Aires. 